\title{
Monitoring of Data from Multiple Sensors Using Android Application and its User Manual
}

\author{
Vishesh $\mathbf{S}^{1}$, Sharath $\mathbf{R}^{2}$, Varun Hebbar $\mathbf{B C}^{2}$, Sripragna $\mathbf{C H}^{2}$, Shreyas $\mathbf{B V}^{3}$, Ramalingesh Godavarthi ${ }^{4}$ \\ B.E, Department of Telecommunication Engineering, BNM Institute of Technology, Bangalore, India ${ }^{1}$ \\ Student, Department of Telecommunication Engineering, Dayananda Sagar College of Engineering, Bangalore, India ${ }^{2}$ \\ Student, Dept of Electronics and Communication Engg, Dayananda Sagar College of Engineering, Bangalore, India ${ }^{3}$ \\ Student, Department of Electronics and Communication Engineering, KSIT, Bangalore, India ${ }^{4}$
}

\begin{abstract}
Today's Smartphones come with an advanced Operating Systems (OS), a swift processor, huge memory space, SD card /external memory card slot, USB, graphic accelerators and many other features to satisfy the needs of the $21^{\text {st }}$ century user. In fact smartphones are portable and battery powered Personal Computers. The widespread adoption of mobile devices such as the smartphones has created tremendous opportunities for business, entertainment, science and technology, sports, stock market, etc. Many useful applications can be easily found in the smartphone and used immediately. The Operating Systems like Android and iOS provide platform for third party applications as well. Today almost all business/ companies/ firms have their own Android or iOS application which can be easily downloaded from the app store and easily installed into the smartphone. The third party application opens up the door to infinite possibilities and nourishes the user's experience. In this paper we present to you the working of the Android application that we have built and discussed in our previous paper [1] "Android Application to Read and Record Data from Multiple Sensors". We also present to you the user manual of the Android application. Embedded system life cycle is unravelled with a real time example.
\end{abstract}

Keywords: Smartphones advanced Operating Systems, Android, Embedded System life cycle, Personal Computers, third party applications.

\section{INTRODUCTION}

Smartphones run on sophisticated Operating Systems like Android [2], iOS [3], Microsoft OS [4] etc. In this paper we have developed an Android application which reads and records any real time sensor values. Android OS supports third party applications [5] developed by any coder with a proper knowledge of Android coding. The developed application can be released into the Android market or Play Store/ Google Play. Google Play is a digital distribution service, operated and developed by Google. It serves as the official application store for Android OS. Users can browse and download applications; both applications provided by Android or third party developed applications and published through Google. These applications may be paid apps or free apps. However, there is no requirement that Android applications must be acquired using the Play Store. Users can also download applications from a developer's website or through third party app store alternative. Play Store applications are self-contained Android Package Files (APK) that can be installed to the device. On Android devices "Unknown Source" feature in settings allow the users to bypass the Play Store and install APK's from other sources. The applications can be installed to the phone's internal memory or external storage card.

\section{WORKING OF THE ANDROID APPLICATION AND USER MANUAL}

- Select the installed Android application "Sense_graph" from the user menu.

- Please give a file name in the text box provided.

- Press on the button with the Bluetooth symbol.

- If the Bluetooth of the device is switched OFF (default) a notifier message will be displayed stating "Please Enable Bluetooth".

- Please switch ON the Bluetooth [6] of the device.

- A list of available Bluetooth devices will be displayed.

- Select the desired Bluetooth device.

- Pair with that device/add that to the paired devices.

- Enter security key to start the wireless communication between the sensors and the smartphone.

- If no Bluetooth device is found, a warning message stating "no Bluetooth device found" will appear. 
- If at any point the paired device is not connected via Bluetooth at that instant an Error 507 message will pop up stating, "Unable to connect. Is the device turned on?"

- If connected properly, two way communication is established and the sensor values can now be read and recorded.

- Select the desired sensor button out of sensor 1 , sensor 2 , sensor 3 , sensor 4 , sensor 5 , sensor 6 , sensor 7 and sensor 8.

- Selecting a sensor button, say sensor 1- sensor 1 values will appear serially and a graph of time vs. amplitude will be plotted.

- $\mathrm{X}$ axis and the corresponding $\mathrm{Y}$ axis values will be displayed in the display box as shown in the figure 1.

- To read sensor $2 /$ sensor $3 /$ sensor $4 /$ sensor $5 /$ sensor $6 /$ sensor $7 /$ sensor 8 , STOP button has to be pressed and desired sensor button is selected and the plotting continues.

- To SAVE the plot at any instant STOP and SAVE button has to be pressed.

- We have made a provision for the plot to be saved in the phone's internal or SD card memory.

- Back button can be pressed to exit the application.

- An Alert message stating "Are you sure you want to close the application" will pop up with "Yes" and "No" buttons.

- Choose "Yes". Figure 1 shows the Android application "Sense_graph" developed by Konigtronics Pvt Ltd.

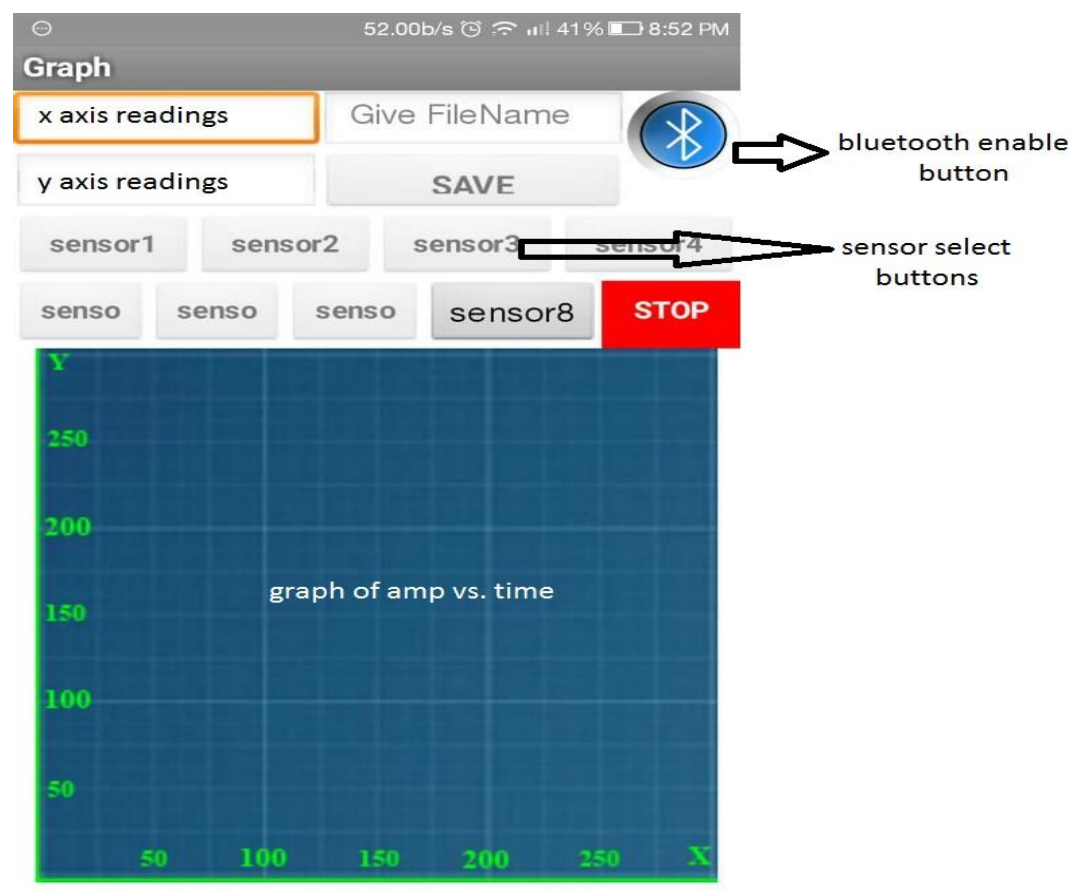

Figure 1 Android application "Sense_graph"

\section{III.STEPS OR WAYS TO DOWNLOAD SENSE_GRAPH}

A. Konigtronics Website

- Send a request mail to konigtronics.com [7] for the application.

- An APK file will be sent to the user.

- Use QR code reader or simply save to "_ "option and the APK file will be stored in the selected location.

- Press install button to install the application on your smartphone.

B. Android Market

- The application will be released into the Android Market.

- Press the purchase option and download after payment.

- Press the install button to install.

C. On Share-it

- The application can be shared using Share-it.

- A unique key/ user ID will be given for new installer after purchase. 
Figure 2 shows the purchase of APP through Konigtronics Website. Figure 3 shows the purchase of APP through Android Market [8]. Figure 4 shows the sharing of APP through Share-it.

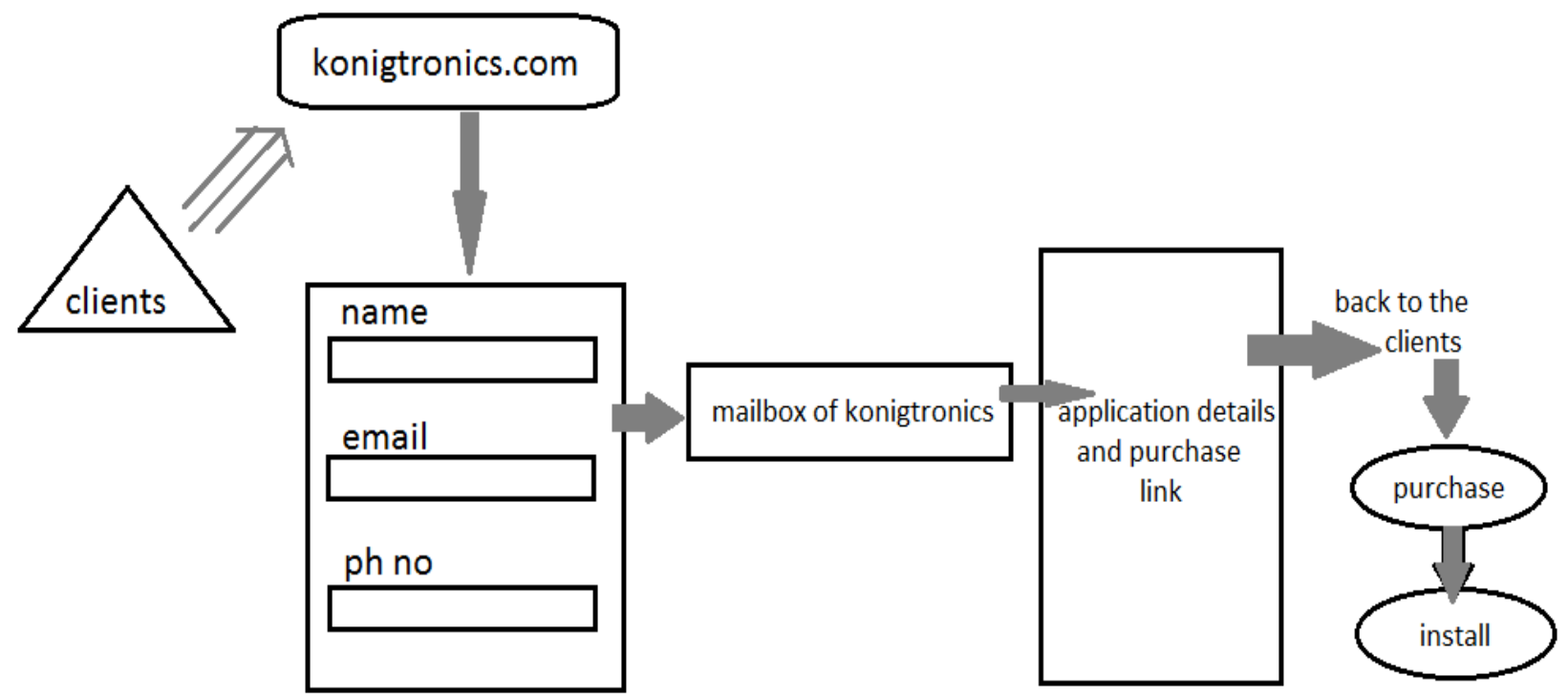

Figure 2 shows the purchase of APP through Konigtronics Website

\section{IV.EMBEDDED SYSTEM LIFE CYCLE}

In the development of the embedded system we follow the Iterative EDLC model as shown in figure 5. There can be up to $n$ cycles, where $n=1,2,3,4 \ldots$ and this terminates in the $n^{\text {th }}$ cycle.

\section{Android Market}

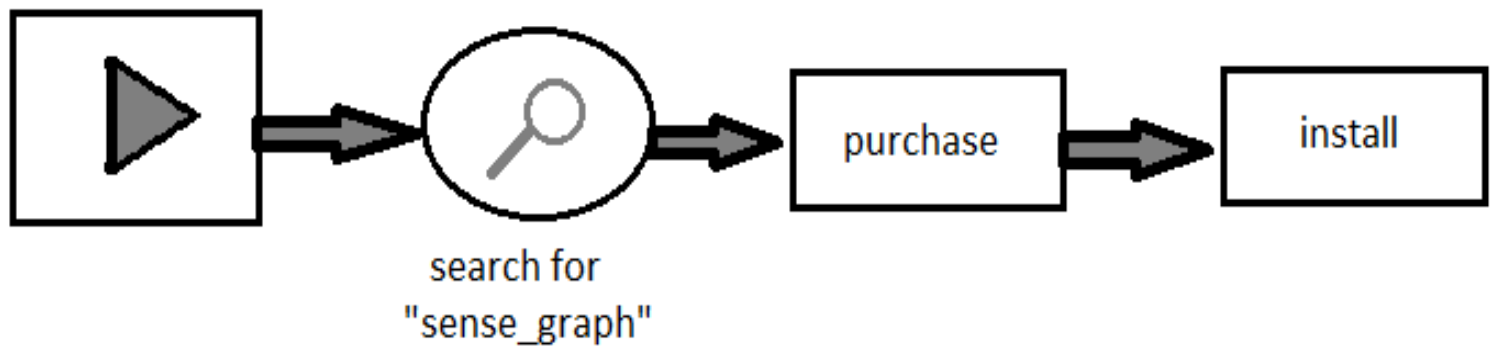

Figure 3 shows the purchase of APP through Android Market

\section{RESULTS AND FINDINGS}

Figure 6 shows the result of temperature sensor placed in a particular region. A graph of degree C vs. time is plotted on the canvas and the temperature reading is constant at 31 degree $\mathrm{C}$ at a single place for a certain time interval. The values of $\mathrm{X}$ and $\mathrm{Y}$ axes is displayed in the text display box. There is a provision to enter the file name before saving it. Once the STOP button is pressed the plotting freezes and the plot can be saved to the internal memory or SD card. A screenshot of the plot can also be taken for detailed readings as shown in figure 6.

\section{VI.CONCLUSIONS}

It would be fascinating if serial read/write from real time sensors can be done on a smartphone. A Smartphone is a wireless, portable and handheld device making it preferable over bulk and non-portable Personal Computers. In this paper we have built an Android application which performs real time monitoring of sensor values and also records it/saves it to the system memory. 
International Journal of Advanced Research in Computer and Communication Engineering ISO 3297:2007 Certified

Vol. 6, Issue 5, May 2017

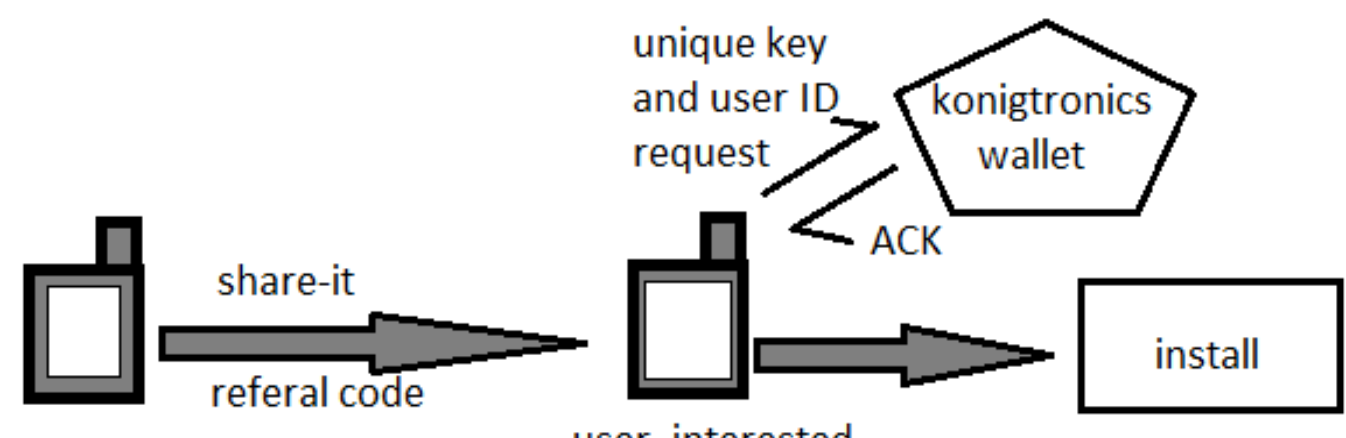

user with

purchased

app

\section{user interested}

in purchase

Figure 4 shows the sharing of APP through Share-it

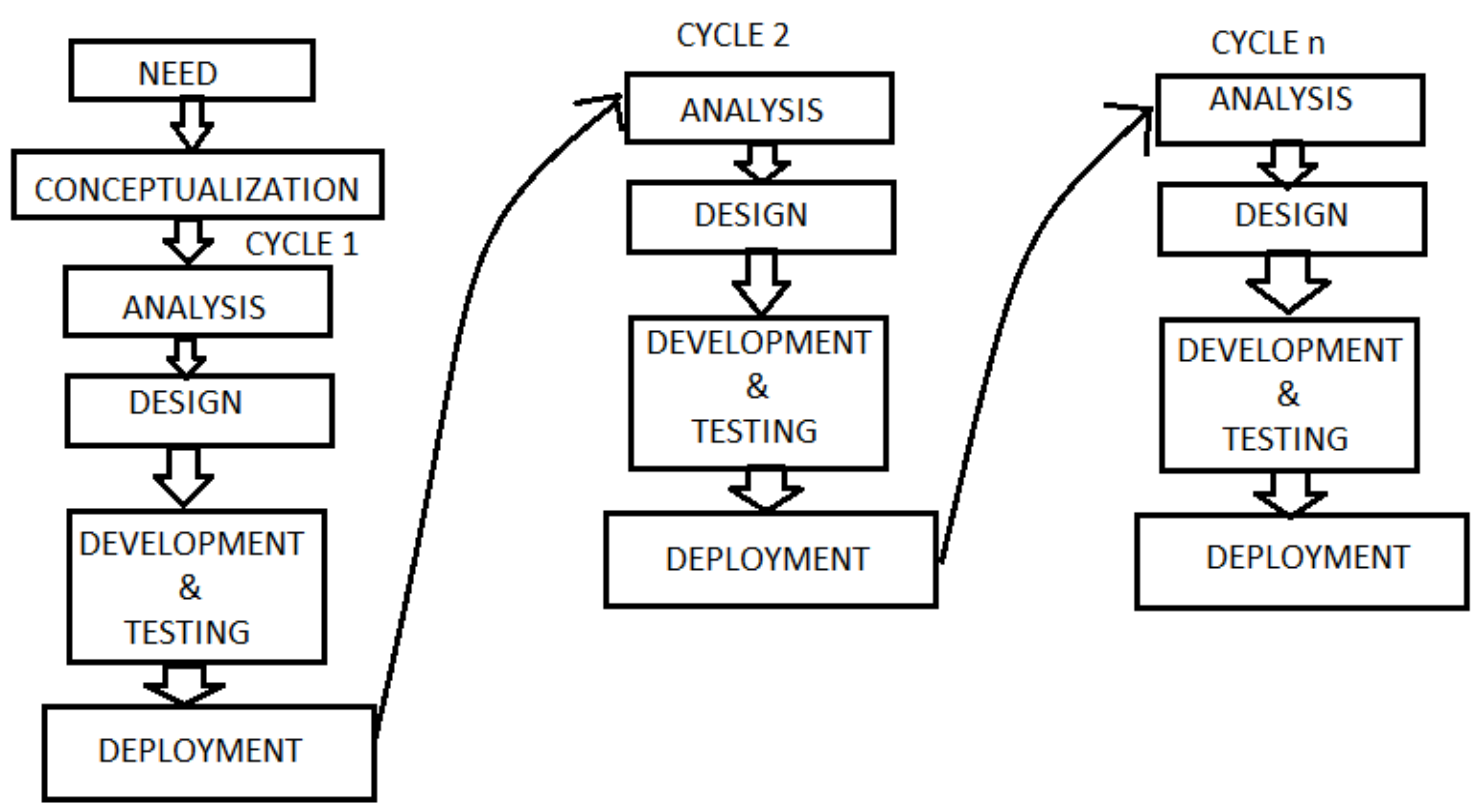

Figure 5 EDLC iterative model

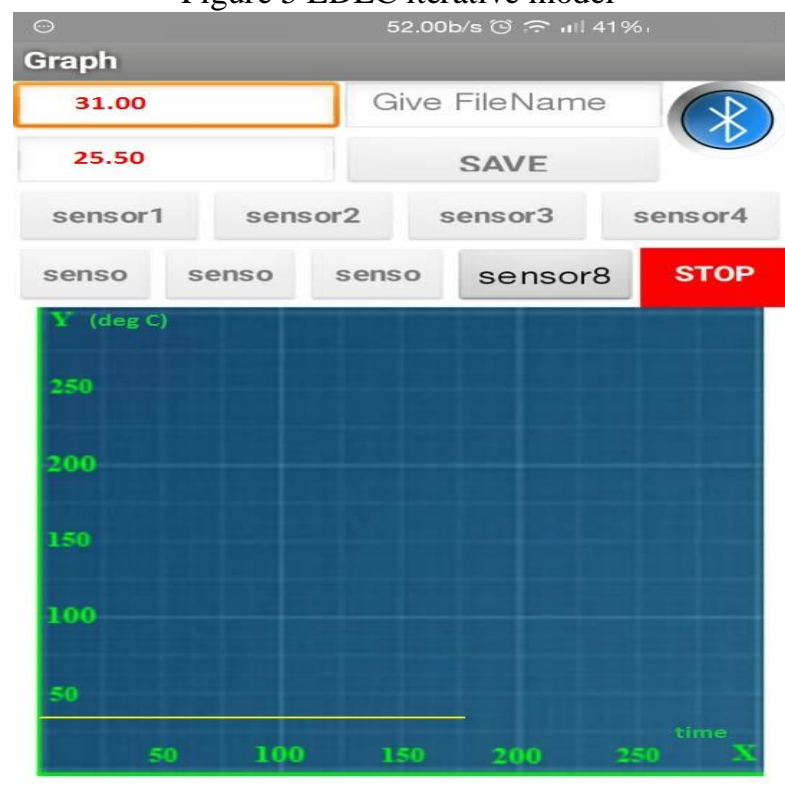

Figure 6 screenshot of the plot 


\title{
REFERENCES
}

\author{
[1] “Android Application to Read and Record Data from Multiple Sensors" IJARCCE- DOI: 10.17148/IJARCCE.2017.6587 \\ [2] Android- https://www.android.com/intl/en_in/ \\ [3] iOS- https://www.apple.com/in/ios/ios-10/ \\ [4] Microsoft OS- https://www.microsoft.com/en-in/windows/ \\ [5] Third party apps- https://support.google.com/plus/answer/2485911?hl=en \\ [6] Bluetooth technology website- https://www.bluetooth.com/ \\ [7] konigtronics.com \\ [8] Android apps on Google Play- https://play.google.com/store/apps?hl=en
}

\section{BIOGRAPHIES}

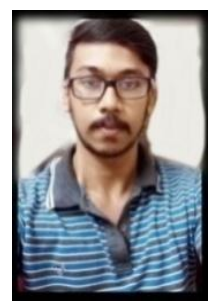

VISHESH $\mathbf{S}$ born on $13^{\text {th }}$ June 1992, hails from Bangalore (Karnataka) and has completed B.E in Telecommunication Engineering from VTU, Belgaum, Karnataka in 2015. He also worked as an intern under Dr Shivananju BN, Department of Instrumentation, IISc, Bangalore. His research interests include Embedded Systems, Wireless Communication and Medical Electronics. He is also the Founder and Managing Director of the company Konigtronics Private Limited. He has guided over a hundred students/lecturers/interns/professionals in their research works and projects. He is also the co-author of many International Research Papers. He is currently pursuing MBA. Presently Konigtronics Private Limited has extended its services in the field of Real Estate, Webpage Designing and Entrepreneurship.

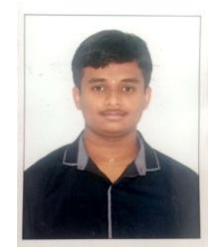

SHARATH R hails from Bangalore, Karnataka. He is currently pursuing BE in Telecommunication Engineering at DSCE, Bangalore. His research interests include Embedded Systems and missile technology.

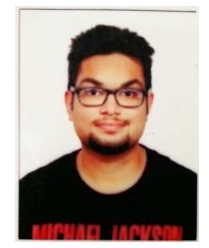

VARUN HEBBAR BC hails from Bangalore, Karnataka. He is currently pursuing BE in Telecommunication Engineering at DSCE, Bangalore. His research interests include Embedded Systems and android coding.

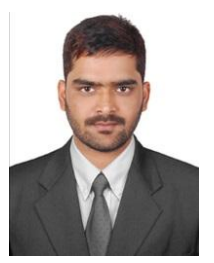

SHREYAS BV hails from Bangalore, Karnataka. He is currently pursuing BE in Electronics and communication Engineering at DSCE, Bangalore. His research interests include android coding and robotics.

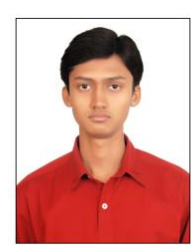

RAMALINGESH GODAVARTHI hails from Bangalore, Karnataka. He has completed BE in Electronics and communication Engineering at KSIT, Bangalore. His research interests include Embedded Systems and Python programming. He has also done a project on Real time satellite tracking using Python. He is pursuing his MS in Electronics Engineering and specialised in Communication Systems Engineering from Germany.

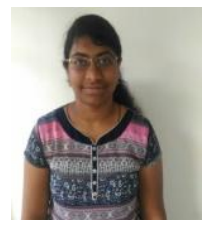

SRIPRAGNA CH hails from Bangalore, Karnataka. She is currently pursuing BE in Telecommunication Engineering at DSCE, Bangalore. Her research interests include Embedded Systems and android coding. 